\title{
EDITORIAL
}

\section{New Antiepileptic Drugs-Discovery, Development, and Update}

When asked to create a Neurotherapeutics issue on antiepileptic drugs (AEDs), we decided that our first priority would be to update the community on AEDs in development. This has been done before by both of usDr. Porter created a volume with Brian Meldrum in $1986^{1}$ (only 20 years ago!) and Dr. French has had a semiannual course entitled Antiepileptic Drug Trials for more than a decade (the next will be in Miami, March 21-24, 2007), which has spawned several books on the same theme. ${ }^{2,3}$ Therefore, we focused on drugs currently in development. Fortunately, for patients with epilepsy the pipeline for new antiepileptic drugs is very rich. Only those drugs (16-18) that had reached a clinical stage, even if only in human volunteers, were considered. Each of these drugs is described in this volume. Except for one or two others that are just entering clinical trials, this review issue is complete. We are extremely grateful to the authors of these chapters.

But a description of potential drugs alone, while interesting, would have been too narrow a document for Neurotherapeutics, which has become, under the editorial guidance of Alan Faden, a first-class review journal. Thus, we decided that an integral part of the issue would be inclusion of a substantial first section of the volume on the "state of the art" in discovery and development of new AEDs.

We begin with an insightful introduction to AEDs by Steven Schachter. He considers the general treatment principles, reviews all the drugs currently available, and makes suggestions regarding AED selection. He also addresses treatment outcomes.

We then turn to the discovery of new AEDs. Few have had as much experience in this area as Steve White, who for many years has managed the National Institute of Neurological Disorders and Stroke contract for AED discovery. Dr. White and co-authors explore the process of identification of new compounds and also address the potential pitfalls of using available animal models to choose the most promising candidates.

In seeking authors for the difficult task of discussing the molecular targets for AED development, we were very fortunate to enlist two distinguished scientists, Mike Rogawski and Brian Meldrum. Their magnum opus provides a comprehensive review not available elsewhere. As such, this outstanding basic science review is the longest yet published in this journal.
Few understand the international arena of clinical drug development better than Bernd Schmidt, who has been involved in AED development for decades. He reviews clinical development of AEDs in adults, and tackles such issues as how to run a development program and the potential pitfalls involved.

Despite the fact that pediatric epilepsy comprises so much of what we see of the disorder clinically, it is often left out of the mainstream of clinical development. Betsy Garofalo has spent a career in AED development, and as a pediatrician is well positioned to address problems associated with studies of AEDs in children. These thorny issues include ethical dilemmas, trial design, and regulatory hurdles.

Finally, we include in our first section a chapter on the nonepilepsy uses of AEDs. Unfortunately, a promising AED may be left on the shelf if it has no other potential clinical utility. Alan Ettinger and Charles Argoff have addressed these issues in a comprehensive fashion.

It is hope that the reader of this volume will get a sense, as we have over recent years, of enormous growth and possibilities in the field of AED development. On the preclinical side, we have seen advancement in molecular targets and the beginning of what may be a steady development in animal modeling of different epilepsies. On the clinical side, a wealth of compounds has been coupled with novel trial designs that encompass a broad spectrum of epilepsy types and populations that may help in selecting the best opportunities. Although there is still much progress to be made, the contents of this volume make it clear that we have come a long way.

Roger J. Porter, M.D. Adjunct Professor of Neurology University of Pennsylvania Philadelphia, Pennsylvania and Adjunct Professor of Pharmacology Uniformed Services University of the Health Sciences Bethesda, Maryland Jacqueline A. French, M.D. Professor of Neurology Chief, Epilepsy Section Assistant Dean for Clinical Trials University of Pennsylvania Philadelphia, Pennsylvania 


\section{REFERENCES}

1. Meldrum BS, Porter RJ (eds): New anticonvulsant drugs. In: Current problems in epilepsy. London: John Libby; 1986.

2. French JA, Dichter MA, Leppik IE (eds). New antiepileptic drug de- velopment: preclinical and clinical aspects. Proceedings of a conference. Miami, Florida, March 1992. Epilepsy Res (suppl) 1993;10: 3-255.

3. French JA, Leppik IE, Dichter MA (eds). Advances in Neurology. Vol. 76. Antiepileptic drug development. Philadelphia, PA: Lippincott-Raven: 1999. 